\title{
$>$ A incompreensão de Bacurau
}

> Bacurau's incomprehension

por Natália Acurcio Cardoso

Mestranda na área de Estética do Departamento de Filosofia da Faculdade de Filosofia, Letras e Ciências Humanas da Universidade de São Paulo (FFLCH-USP). Bolsista FAPESP. E-mail: natalia.acurcio.cardoso@usp.br. ORCID: 0000-0001-6743-2826. 


\title{
FICHA TÉCNICA DA OBRA
}

\author{
Bacurau \\ Direção: Kleber Mendonça Filho; Juliano Dornelles \\ Produção: Emilie Lesclaux; Said Bem Said; Michel Merkt \\ Intérpretes: Sônia Braga; Udo Kier; Bárbara Colen; Thomás Aquino; \\ Silvero Pereira; Karine Teles \\ Roteiro: Kleber Mendonça Filho; Juliano Dornelles \\ Brasil; França: SBS Productions; CinemaScópio; Globo Filmes \\ 2019.
}

$132 \mathrm{~min}$

This world is upside down ${ }^{1}$, diz lentamente um dos estrangeiros, o Michael ${ }^{2}$, e essa frase talvez nos ajude a refletir um pouco sobre o filme Bacurau³ ${ }^{3}$ de Kleber Mendonça Filho e Juliano Dornelles. Quando o filme termina, ao som de Réquiem para Matraga, de Geraldo Vandré, a impressão imediata é de que a música é uma espécie de aviso para aqueles que não esperam nada de um lugar que é considerado insignificante ou simples demais, que não enxergam ali qualquer

\footnotetext{
1 "Esse mundo está de cabeça para baixo".

${ }^{2}$ Interpretado por Udo Kier.

${ }^{3}$ Agradeço ao Alcides Devides Moreno e a Anna Carolina Martins Ribeiro pelas valiosas sugestões e comentários.
} 
possibilidade de insurgência e por isso não perdem por esperar a hora e a vez do protagonismo de onde menos parecia possível.

De início pode surpreender como aquela comunidade, aparentemente pacífica e desarmada, e que sequer tinha uma polícia, tinha dado uma resposta à altura da que lhe estava sendo cobrada, mesmo que essa cobrança tenha exigido que ela desempoeirasse as armas do museu e as colocasse em uso, de forma tão repentina. Quando enfim conseguimos entrar nesse espaço, vemos que há tempos Bacurau sabia que essa luta não poderia ser articulada por ninguém além dela e que era preciso que ela se unisse para que, num movimento orquestral, produzisse alguma resposta efetiva.

Mas voltemos um pouco. Ao longo do filme nos deparamos com imagens atuais da educação abandonada e da falta de água para aqueles que estão tão distantes do poder financeiro e político. Porém, na contramão desse descaso, a escola de Bacurau parece funcionar muito bem, tendo inclusive a melhor biblioteca da região, segundo o prefeito Tony Junior ${ }^{4}$. De cerdo modo, é como se aquilo que dependesse sobretudo do exterior estivesse em estado crítico, como a água, e o que a cidade consegue conduzir em alguma medida por conta própria caminhasse bem, como a escola, o hospital (vemos Tereza ${ }^{5}$ trazendo um estoque de vacinas na sua mala) e o museu, que desempenha um papel bastante intrigante. Assim, desde o início fica claro como há uma problemática em torno da relação entre interno e externo, já que logo nas primeiras cenas ficamos a par dos conflitos que aconteceram na região e como isso afeta a cidade. Mas, de

\footnotetext{
${ }^{4}$ Interpretado por Thardelly Lima.

${ }^{5}$ Interpretada por Bárbara Colen.
} 
início, não vamos muito longe com o real significado de mundo exterior e pensamos apenas nos problemas ainda locais entre a cidade e aquilo que está próximo dela.

Em relação ao museu, primeiro é a dona do bar que, logo depois de observar o João ${ }^{6}$ cheirando a água com gás que ele mesmo abriu, pergunta para os forasteiros se eles vieram visitá-lo, frisando como ele é bom. Um pouco depois, e não por acaso, Tereza repete a mesma pergunta; mas eles não se interessam. A igreja virara um depósito, mas o museu estava conservado - a cidade não abandonara a sua história e, por isso, cabia a Bacurau manter o que parece ser seu verdadeiro santuário. É justamente ali, nesse lugar com acontecimentos do passado, onde a princípio habitava o que não estava mais presente, que a cidade procura a sua defesa, e as armas do museu são agora retiradas de lá e recolocadas em prática. Ele não está morto, e as histórias de luta que estavam sendo ali contadas agora se repetiam e apareciam como necessidade do presente. Porém, essas lutas foram reconfiguradas, e foi necessário que Bacurau se defendesse daquilo que fugia do compreensível, e por isso eles só podiam perguntar: Por que vocês estão fazendo isso?

Os estrangeiros agem com a mesma excitação de um caçador e com a mesma fascinação de um adolescente diante de um jogo de vídeo game ou RPG, e inclusive utilizam a linguagem dessas atividades: se referem às vítimas como alvos, ganham pontos com as mortes, que seguem regras específicas, e chamam a atividade na qual se inscreveram de caça e missão. É curioso como essa imitação

\footnotetext{
${ }^{6}$ Forasteiro de São Paulo, interpretado por Antonio Saboia.
} 
de uma realidade virtual $^{7}$ no campo da realidade efetiva parece passar desapercebida pelos estrangeiros, pois eles continuam agindo como se estivessem em um jogo de simulador: eles apagam a cidade do mapa, avançam pouco a pouco como se passassem de diferentes fases e com isso esperam programar as respostas dos habitantes, como se ali estivessem pessoas submetidas a "leis diferentes daquelas que governam o mundo comum" .

Difícil não lembrarmos do texto "A precessão dos simulacros", de Jean Baudrillard, ao observarmos a forma como os estrangeiros operam no filme. Nesse ensaio, Baudrillard diz que agora a simulação não se dá mais tendo o real como referência ou precedente, tal como se dava antigamente ao construírem, um mapa de um território, por exemplo. “O território já não precede o mapa, nem lhe sobrevive. É agora o mapa que precede o território- precessão dos simulacros [...]"'. Tirar a cidade do mapa, não se interessar pela sua história e desprezar os seus habitantes parece elucidar muito bem o que Baudrillard está dizendo: os estrangeiros impõem a simulação à própria realidade, criando assim aquilo que o autor chama de deserto do real, já que há uma carência do próprio real naquilo está sendo simulado dentro dele. Segundo o autor, é com uma atitude imperialista que os "simuladores atuais tentam fazer coincidir o real, todo o real,

\footnotetext{
${ }^{7}$ Segundo Pierre Lévy, realidade virtual é "um tipo particular de simulação interativa, na qual o explorador tem a sensação física de estar imerso na situação definida por um banco de dados." Pierre Lévy, Cibercultura, 1999, p. 70.

${ }^{8}$ Ao discorrer sobre realidade virtual, Lévy comenta que um mundo virtual pode ou não simular fielmente o mundo real. No filme, parece que os estrangeiros incorporaram tão ao extremo a realidade simulada por eles mesmos que eles não se dão conta que as coisas podem se passar de uma forma diferente da que eles estão esperando. Ao elaboraram os habitantes de Bacurau como se eles fossem ingênuos e totalmente passivos, e não seres humanos comuns, eles não estavam contando com que eles fossem reagir aos ataques, por exemplo. Ibidem, p. 72.

${ }^{9}$ Jean Baudrillard, Simulacro e simulação, 1991, p. 8.
} 
com os seus modelos de simulação" ${ }^{10}$ e um dos motivos seria o total desencanto com a realidade. Essa simulação não precisa ser racional, já que ela não tem mais nenhum lastro com o real, e por isso Baudrillard diz que ela é operacional, pois remete apenas ao seu próprio modelo de comando. No fim vemos como os forasteiros tornaram-se vítimas da sua própria simulação, porque o campo efetivo não estava determinado pelas regras do seu jogo e por isso não podia ser totalmente controlado. Ou talvez havia regras ali que não valiam só para os estrangeiros, como eles imaginavam de início.

Ainda que os estrangeiros mostrem que, por um lado, não há nenhum conflito para eles em dizimar os habitantes de Bacurau ou em matar os forasteiros brasileiros, pois atirar e matar é um meio de canalizar o seu gozo, por outro lado, eles não aceitam qualquer tipo de violência, o que mostra que a compreensão do opositor é sempre mais complexa do que muitas vezes estamos dispostos a aceitar. Michael diz no final do filme que não mata mulheres; Jake ${ }^{11}$ diz que Terry $^{12}$ é doente por ter pensado em matar a ex-mulher; Terry mostra-se nervoso e inconformado por Joshua ${ }^{13}$ ter matado uma criança, e chama Michael de nazista por ele não estar igualmente revoltado contra tal fato. ${ }^{14}$

\footnotetext{
${ }^{10}$ Jean Baudrillard, Op. Cit., p. 8.

${ }^{11}$ Interpretado por James Turpin.

${ }^{12}$ Interpretado por Jonny Mars.

${ }^{13}$ Interpretado por Brian Townes.

${ }^{14}$ Esse momento do filme parece bastante provocativo com o cinema americano, já que a luta contra os nazistas em vários filmes de Hollywood tem por trás, como aquilo que a sustenta, muito mais um sentimento de orgulho nacionalista contra os inimigo de guerra do que uma revolta real contra esse regime, e vemos Michael se defendendo do ataque do seu colega dizendo: I'm more american than you are [Eu sou mais americano do que você].
} 
Como já disse acima, os estrangeiros estavam fazendo uma coisa que a cidade tinha dificuldade de entender e, por isso, os moradores perguntavam o motivo de tal violência estar sendo cometida contra eles. No entanto, não podemos esquecer que a forasteira Maria ${ }^{15}$, durante a reunião na fazenda na qual os brasileiros se descobrem brasileiros, curiosamente faz para os estrangeiros a mesma pergunta do povo de Bacurau: Por que vocês estão fazendo isso? Ela não entende por que aquela violência, de início psicológica, está sendo cometida contra ela e João. Maria usa o pronome possessivo na primeira pessoa do plural para se referir à missão, ${ }^{16}$ como se ela e João também integrassem aquele nós, que é de fora e distante daquele lugar, com origens superiores que os autorizam a tirálo do mapa.É como se houvesse graus de existência, e algumas contassem menos, ou melhor, contassem pontos em um jogo macabro. Mas os brasileiros estavam fora do jogo, tanto por não respeitarem as regras (eles não usam armas vintage, por exemplo) como por não serem geneticamente e geograficamente aptos para fazerem parte da equipe.

Mas pensemos sobre aquela pergunta e o sentido de ela ser repetida por personagens diferentes e que inclusive estão em confronto. Ao perguntarmos o porquê de uma ação mostramos ao menos que não entendemos o que a motiva ou talvez que não vemos sentido no resultado do que está sendo realizado. Há algo que escapa da nossa compreensão e talvez seja justamente sobre isso que devamos pensar: sobre como esse escapismo pode estar encobrindo uma

\footnotetext{
${ }^{15}$ Interpretada por Karine Teles.

${ }^{16}$ Ela se refere a missão como "our mission" ("nossa missão") e, imediatamente, é ironizada por Kate, que pergunta: "Our mission?".
} 
incompreensão anterior que talvez diga respeito ao sujeito que formula a pergunta.

Maria não entende por qual motivo os estrangeiros querem constrangê-la e qual é o ganho deles com isso, já que em princípio não faz sentido agredir quem está de alguma forma te ajudando para alcançar um objetivo comum. Porém, para nós, que estamos assistindo a cena, chega a ser risível a ingenuidade dela, pois fica claro como houve uma inversão do quadro de violência que há pouco ela e João tinham cometido contra Bacurau (seja pela postura arrogante e discriminatória que eles demonstraram na cidade, seja pelas duas mortes pelas quais eles foram responsáveis) e que agora ela havia se tornado vítima daquilo que ela mesma permitia que fosse realizado contra aqueles que para ela eram outros totalmente distintos e inferiores. Ou seja, aquilo que é uma forma de cegueira, que escapa aos dois, se voltou contra eles da pior forma possível, e rapidamente eles viraram um alvo dos estrangeiros.

Porém, o que está por detrás da mesma pergunta quando ela é feita pela voz de Bacurau? Há algo ali que, para nós, também mostre uma incompreensão maior, algo que também lhes escapa? Pelo menos de início, os motivos da incompreensão de Bacurau parecem muito menos óbvios do que a dos forasteiros. Eles não participam daquele ataque, então é como se, ao serem surpreendidos, só lhes restasse uma pergunta dessa natureza, porque os acontecimentos estavam realmente dentro de uma zona do total desconhecido. Mas não haveria também ali algo que nós, espectadores, deveríamos notar para que possamos entender como Bacurau faz a mesma pergunta de Maria? 
Conversando sobre o filme, ouvi muitas vezes dois comentários opostos: ou que Bacurau era um lugar utópico, no qual uma população plural vivia pacificamente aceitando as diferenças entre si e sendo combativa apenas na medida do necessário, ou que esse era exatamente o problema do filme, que retratou de forma fácil um lugar idealizado sem possibilidade de dialética, já que não tinha nenhuma negatividade ali. Por mais que eu não concorde com esses comentários, que no fim se assemelham por entender que o filme quer oferecer um exemplo de sociedade matriarcal, coletivista e sem conflitos internos, há de se ressaltar que a cidade apresenta uma dinâmica própria bastante interessante.

Que estamos diante de algo diferente já é mostrado assim que Tereza chega na cidade e Damiano ${ }^{17}$ lhe oferece o psicotrópico, que se parece muito mais com uma semente do que com os remédios de tarja preta que foram doados para a cidade, e isso anuncia que ela está entrando em uma realidade outra, fundada no sertão de Pernambuco. De fato, vemos gestos de cuidados serem praticados, como os alimentos compartilhados, o respeito pela autonomia da população em fazer escolhas depois de serem instruídas e figuras femininas que são centrais na cidade e que fogem da representação normativa de força que normalmente encontramos em outros lugares. Ou seja, é como se Bacurau tivesse uma espécie de ruptura com o exterior e vivesse de outra forma.

Porém, para confrontar essa ideia de exposição de uma cidade ideal, acho importante lembrar daquela cena em que os habitantes de Bacurau se recolhem em suas casas com a visita do prefeito no início do filme e não fazem nada para impedir que uma das prostitutas seja levada por ele e seus capangas, mesmo que

\footnotetext{
${ }^{17}$ Interpretado por Carlos Francisco.
} 
ela estivesse aflita e deixando claro que não queria ir. A cafetina apenas repete que o pagamento deveria ser adiantado, mostrando total descaso com a situação de violência que acontecia ali, e há apenas um homem que pede para que não a levem. Estão levando Sandra ${ }^{18}$ à força, grita sua amiga em apelo, mas só Domingas $^{19}$ aparece, e faz uma ameaça caso eles a machuquem. Quando Sandra retorna, deparamo-nos com o silêncio constrangedor da cidade diante do seu estado deplorável.

Outro fator que mostra como a cidade não era esse exemplo ideal que alguns querem acreditar (e isso não é uma crítica ao filme, mas só quero salientar como algumas pessoas têm dificuldades em apontar o negativo naquilo que elas querem acreditar e enxergar como um belo exemplo), diz respeito ao papel central de Pacote ${ }^{20}$ no filme. Algumas cenas ficam um pouco misteriosas e não sabemos muito bem qual era a profissão que Pacote exercia de fato, se ele estava apenas atuando naqueles vídeos de sucesso, se ele era um matador de aluguel ou, ainda, se ele matou pessoas aleatórias para gravar os tais vídeos, o que de certa forma teria algum grau de semelhança com a atividade dos estrangeiros, ainda que seguindo outras regras. O que sabemos é que ele fez algo de que agora aparentemente se envergonha e não quer nem falar sobre isso, mas a cidade se entretém com os seus vídeos de violência, que também possuem uma estética semelhante a jogos de vídeo game, e os assistem em um telão no centro da vila. Ou seja, uma das coisas que diverte e que é capaz de reunir os cidadãos no seu momento livre é uma seleção dos melhores vídeos de assassinatos veiculados na

\footnotetext{
${ }^{18}$ Interpretada por Jamila Facury.

${ }^{19}$ Interpretada por Sônia Braga.

${ }^{20}$ Interpretado por Thomás Aquino.
} 
internet que têm um dos seus habitantes como protagonista, o que mostra que Bacurau não estava tão afastada assim desse mundo que agora ela questiona e não consegue entender. No final do filme, vemos que a TV estava ligada em uma transmissão ao vivo de execuções públicas em São Paulo. Ao mesmo tempo que essa cena nos mostra porque São Paulo é um paiol (não que precisássemos de alguma explicação), também podemos deixar em aberto se essa não é mais uma das características intrigantes dos habitantes de Bacurau, que dão audiência para um programa televisivo dessa natureza.

Com isso tudo já podemos desmistificar um pouco esse vilarejo de pessoas totalmente tranquilas e pacíficas que foram atacadas e agora são obrigadas a responder da mesma forma. Acredito que essa possibilidade de desmistificação da cidade, que aparece à revelia tanto dos forasteiros quanto de alguns espectadores que preferem não pensar sobre certos acontecimentos do filme para sustentar uma certa idealização, explicitam a complexidade desse filme. Talvez isso nos mostre como uma vilazinha lá do interior do Pernambuco, aparentemente isolada, está totalmente integrada nas dinâmicas globais do seu tempo, e como de início somos tomados pela ideia de que aquele lugar é uma brecha, um respiro, que se abriu na ordem comum instaurada em nossas vidas. Vemos como Bacurau faz parte de um todo e que, por mais que a cidade tenha suas particularidades e seus méritos, ela não está totalmente apartada daquilo que parecia ser seu outro externo, totalmente rompido com seu interior. Ou seja, é como se a cidade de certa forma participasse de todo esse ciclo de violência que lhe atingiu. 
Quando Michael diz que o mundo está de cabeça pra baixo, ele chega a essa conclusão porque as coisas nem sempre são o que esperamos. De uma forma completamente diferente ao que me suscitou a música de Vandré enquanto deixava a sala do cinema, eu me pergunto agora se aquele sujeito que não entendeu e que não perde por esperar não é também Bacurau. No fim, da forma mais dura possível, a cidade foi colocada diante do seu outro, que acabou mostrando que era na verdade uma parte, ainda que muito pequena, dela mesma. Esse outro, que ela tem dificuldade de compreender, talvez não fosse assim tão diametralmente oposto de si como de início eu queria acreditar e, por isso, a primeira reação é o total repúdio de um e o aplauso do outro. Hegel é um filósofo que nos mostra muito bem como a consciência resiste e sofre para enxergar que aquilo que ela toma como um outro totalmente distinto e diferente de si é, na verdade, um saber dela mesma. O reconhecimento do outro como parte integrante da consciência é necessário para que ela possa superar essa negatividade e assim criar uma nova figuração de si. Talvez seja importante refletirmos mais sobre o significado e as reais consequências desse todo indissociável e complexo, já que o encontro e o conflito entre suas partes são iminentes e, como o filme nos alerta, this is only the beginning ${ }^{21}$.

\footnotetext{
${ }^{21}$ "Isso é apenas o começo". Essa é a última frase dita por Michael antes de o enterrarem vivo no local que foi cavado por Lunga (Silvero Pereira) e outros habitantes da cidade. Aparentemente, esse local já existia e estava apenas soterrado.
} 


\section{Referências}

BAUDRILLARD, Jean. Simulacro e simulação. Tradução de Maria João da Costa Pereira. Lisboa: Relógio d’água, 1991.

LÉVY, Pierre. Cibercultura. Tradução de Carlos Irineu da Costa. São Paulo: Editora $34,1999$.

\section{Referência para citação desta resenha}

CARDOSO, Natália Acurcio. A incompreensão em Bacurau. Revista PHILIA | Filosofia, Literatura \& Arte, Porto Alegre, volume 2, número 1, p. 615 627, junho de 2020. 